\title{
MOVER O OLHAR SOBRE CIRCULAÇÕES DA ARTE E RECEÇÃo
}

\author{
Idalina Conde \\ Centro de Investigação e Estudos de Sociologia, ISCTE - Instituto Universitário de Lisboa, Portugal
}

\begin{abstract}
ReSUMO
Contribuição sobre culturas móveis, este texto aborda circulações físicas, visuais e imaginárias da arte com passagem do museu e de exposições para o espaço público. Assim, arte de indoors para outdoors com mutações que atravessam os quadros da visitabilidade, semiologia, mediações e modos de perceção versus receção. Algumas recriações de Las Meninas de Diego Velázquez e Zodiac Heads/Circle of Animals de Ai Weiwei são exemplos em contraponto que ilustram a problemática da mobilidade, com metamorfoses e itinerâncias. Mover o olhar significa seguir essas viagens como um salto interpretativo sobre contextos e relações com a arte.
\end{abstract}

\section{PaLAVRAS-ChAVE}

arte; mobilidade; receção; Las Meninas de Diego Velazquez e recriações; Zodiac Heads/Circle of Animals de Ai Weiwei

\section{MOVING THE GAZE ON ART CIRCULATIONS AND RECEPTION}

\begin{abstract}
As a contribution about mobile cultures, this text addresses physical, visual, and imaginary circulations of art with passage from the museum, and exhibitions, to the public space. Thus, art from the indoors to outdoors, with which mutations in frames of visitability, semiology, mediations, and modes of perception vs. reception. Some recreations of Diego Velazquez's Las Meninas parallel to Zodiac Heads/Circle of Animals by Ai Weiwei are contrasting examples to illustrate the issue of mobility, with metamorphoses and itinerancies. Moving the gaze means to follow such journeys as a interpretative leap on contexts and relations with art.
\end{abstract}

\section{KEYWORDS}

art; mobility; reception; Diego Velázquez's Las Meninas/The Maids of Honour and recreations; Ai Weiwei's Zodiac Heads/Circle of Animals

\section{MobILIDADE F ARTE EM PÚBLICo}

Las Meninas, ou A Família de Filipe IV (1656), é o quadro mais célebre, fascinante e enigmático de Diego Velázquez (1599-1660). Poucas obras equivalem a esta "metapintura ou hiperícone" que também se recorda como referência para a epistemé da representação desde a sua evocação por Michel Foucault na abertura de As palavras e as 
coisas (1966/1981)'. Com tudo o que se dissertou sobre Las Meninas, a sua viagem por iconosferas e museus imaginários, incluindo em recriações de artistas, Las Meninas é uma obra em movimento, para além do quadro no Museu do Prado em Madrid (Museo Nacional del Prado, 2013; Portus, 2013; Stratton-Pruitt, 2002, 2004).

Eis a razão para "as" trazer a este texto ${ }^{2}$ sobre a mobilidade em arte nos dois sentidos de metamorfose e itinerância. Circle of Animals/Zodiac Heads (2010) de Ai Weiwei será o contraponto, díspar na substância mas similar pela itinerância que transforma frames da experiência (Goffman, 1974), por exemplo, visitabilidade, semiologia das obras, mediações para as entender e modos de perceção versus receção. De resto, a receção bifurca-se de receção na arte entre artistas, pares, mediadores, à receção da arte no espaço (do) público (Conde, 2014a). Os dois planos comparecem no texto, desde o primeiro em recriações de Las Meninas ao segundo em grande parte na reflexão sobre a arte em público (Conde, 2015c).

O termo ajusta-se aos exemplos que envolvem - mas não apenas - formas de arte pública. Constituem um tema com debates sobre a relação da arte pública com a cidade e a cidadania contemporânea (Andrade, 2010; Caeiro, 2014) ${ }^{3}$, e tema com acuidade para as cidades criativas que se tornaram "ecologias axiomáticas" (Conde, 2018). A abordagem no texto pressupõe o tema mas estende-se a outros aspetos e incide principalmente em trânsitos. Ou seja, circulações físicas, visuais, simbólicas e imaginárias de obras de arte, incluindo a passagem do museu (e da moldura de exposições) para o espaço público. Por sua vez, alarga-se à semiosfera no ciberespaço por onde se encontram imagens de Las Meninas e Animals, Velázquez e Wei Wei. Embora aqui não se desenvolva o plano digital, é um esteio de culturas móveis e ligado com novas criações de arte pública (Abreu \& Castro, 2017).

Mover o olhar significa seguir aquelas circulações e constitui um salto interpretativo com a problemática da mobilidade menos contemplada nos estudos sobre arte e receção. Com efeito, enquanto que a mobilidade se tornou keyword (Salazar \& Jayaram, 2016) para o nosso tempo em que tudo viaja física e/ou virtualmente (Bal \& Hernández-Navarro, 2011; Conde, 2018), nesses estudos permanece o modelo intramuros com a paragem contemplativa de públicos frente a obras. Contudo, no quotidiano avultam outros contextos, movimentos e relações com a arte.

\footnotetext{
' Epistemologia de uma ordem de perceção, saber e poder. O recurso a obras-paradigma, como Las Meninas por Michel Foucault, torna-as hiperícones que fundamentam um pensamento como imagens visuais (ícones) e mentais (hiper). Pertencem à categoria autoreflexiva de metaimagens ou metapinturas (Grønstad \& Vågnes, 2006; Michell, 1994). Tem-se olhado desse modo para Las Meninas e os seus enigmas, com glosas e descentramentos de Michel Foucault entre diversas perspetivas (Ancell, 2013; Gugleta, 2011; Nikolov, 1998; Orellana, 2014; Villegas, 2010; Wicks, 2010; Wilder, 2014).

${ }^{2}$ Texto a partir de um capítulo em Reconhecimento em arte: passagens de um percurso (Conde, 2014a) e com apresentação parcial das imagens em "European iconographies for cultural literacy" (Conde, 2015b).

3 Com extensa bibliografia sobre tipologias, contextos, sentidos e públicos da arte pública, de que apenas se apontam alguns títulos a reunir aos citados no texto (Athanassopoulos \& Mahiou, 2012; Baldini, 2014; Calvário, 2008, 2009; Finkelpearl, 2001; Gheorghe, 2010; Sequeira, 2008).
} 


\section{LAS MENinaS COM QUE VIAGENS?}

Começando por Las Meninas, por onde andam para além do quadro no Museu do Prado? Antes de mais, e praticamente desde sempre, andam em incontáveis reproduções e comentários que assim transportam um ex-libris do cânone em museus imaginários e virtuais (Delroche, 2001; Malraux, 1965/1997). Desde há muito, também nos imaginários de artistas como Pablo Picasso (1881-1973) que fez 58 variações sobre Las Meninas em 1957. Graças à metamorfose do "alquimista" Picasso (Jiménez-Blanco, 2008; Lucero, 2010), Las Meninas viajaram do Prado em Madrid para o Museu Picasso em Barcelona onde estão essas recriações ${ }^{4}$.

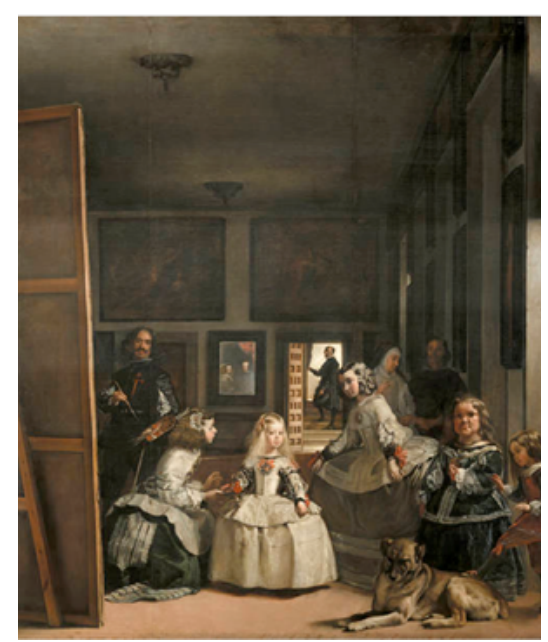

Figura 1: Diego Velázquez, A Família de Filipe IV ou Las Meninas, óleo sobre tela, 3,18 m x 2,76 m, 1656, Museu do Prado, Madrid

Créditos: Museu do Prado

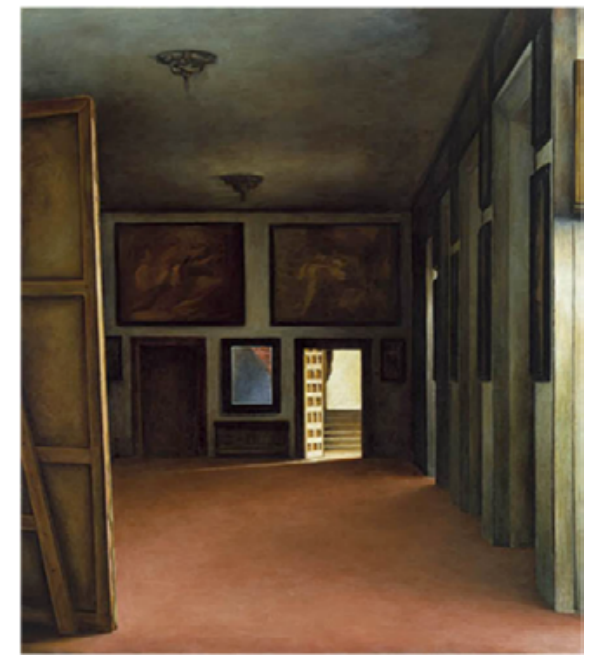

Figura 2: Sophie Matisse, Las Meninas, óleo sobre tela, $177.8 \times 152.4 \mathrm{~cm}, 2001$

Créditos: Sophie Matisse

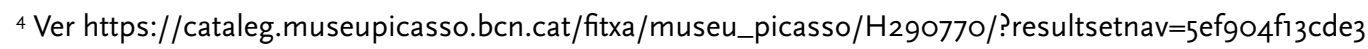


Picasso fez, então, as suas "meninas" em alternativa às de Velázquez, mas a metamorfose artística varia consoante os autores. A sua relação com o referente pode ir do culto a alguma ironia ou iconclasmo que em todo o caso reafirma o cânone como lugar de passagem: a presença obsidiante de Velázquez e de Las Meninas na história da arte.

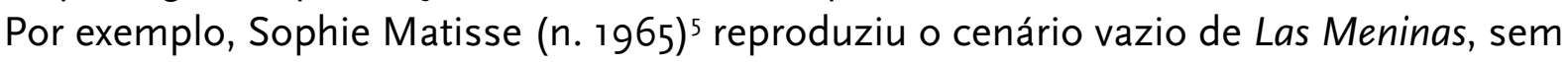
elas nem o auto/retrato de Velazquez. Pintora conhecida por subtrações que fez de quadros-ícones, com a "pessoa desaparecida", também tem uma variação sobre a Monalisa sem a dita e com o título The Monna Lisa (Be back in 5 minutes) (1997). Quanto à obra de Velázquez, deixou o despojamento, literamente imagem aberta que se pode repreencher com figuras imaginárias em que, de resto, se tornaram muito Las Meninas.

De variações pictóricas a fotográficas, Thomas Struth (n. 1954) olha para o "museu como musa" (McShine, 1999). Esse olhar redobra-se sobre o ícone e respetivo culto quando Thomas Struth fotografou públicos no Museu do Prado, e com meninas de grupos escolares frente a Las Meninas. É uma imagem dúplice (Liljegren, 2012) que tanto mostra modos de ver e ritualizações da visita quanto o próprio artista-fotógrafo a re/ encontrar na obra de Vélasquez um punctum ${ }^{6}$.

Comecei a tirar fotografias às pessoas em museus no início dos anos 1990. Fui ao [Museu] do Prado, em Madrid, e fiquei siderado com uma pintura, em especial, Las Meninas de Velásquez. Estava tão próxima dos meus próprios interesses. Pensei "Jesus Cristo, porque é que ninguém me falou disto?" E, contudo, nunca a fotografei até 2005 . Não sei porquê. Quando voltei a ela, isso marcou um momento de evolução em mim. Decidi que eu tinha que tentar algo diferente: tinha de permanecer nos grupos de observadores para criar uma maior intimidade entre as pessoas a ver o quadro e os representados nele.

Eu trabalhei lá sete dias, oito horas por dia, e reparei que os grupos escolares ficavam muito perto da imagem, quase a tocá-la com os seus cotovelos. Gosto dos dois tipos [à esquerda] nesta imagem que parecem muito céticos sobre o que o guia está dizer sobre o quadro. Acho isso divertido. Evidentemente, eles desconfiam. Talvez preferissem tomar uma cerveja.

Tive o meu tripé montado sobre rodas para poder mover-se mais espontaneamente. Mas, como a câmara era bastante grande, ainda assim eu era muito notado. Algumas pessoas acharam que eu era o fotógrafo do museu, e alguns até me reconheceram. Um japonês aproximou-se e perguntou:

\footnotetext{
${ }^{5}$ Sophie Matisse, bisneta de Henri Matisse (1869-1954) e neta de Alexina "Teeny" Duchamp (1906-1995), segunda mulher de Marcel Duchamp (1887-1968).

${ }^{6}$ Termo de Roland Barthes (1980) para o detalhe ou acaso que suscita atenção e emoção numa imagem fotográfica em contraponto com o studium, panorama para o interesse mais conveniente e gosto médio. A imagem acima encontra-se também em Fróis (2008). Sobre Museum Photographs e o trabalho do artista em geral, cf. algumas referências (Schmickl, 2005; Struth \& Belting, 1993/2005; Struth \& Bezzola, Lingwood, Kruszynski, 2010; Struth \& Diego, 2007).
} 
"vem da Alemanha?" Eu disse que sim, e ele: "então deve ser o Thomas Struth". Quando acabei, pensei: "certo, é tempo de deixar este tema. Não posso manter-me mais disfarçado". (Struth \& Benedictus, 2008, p. 1).

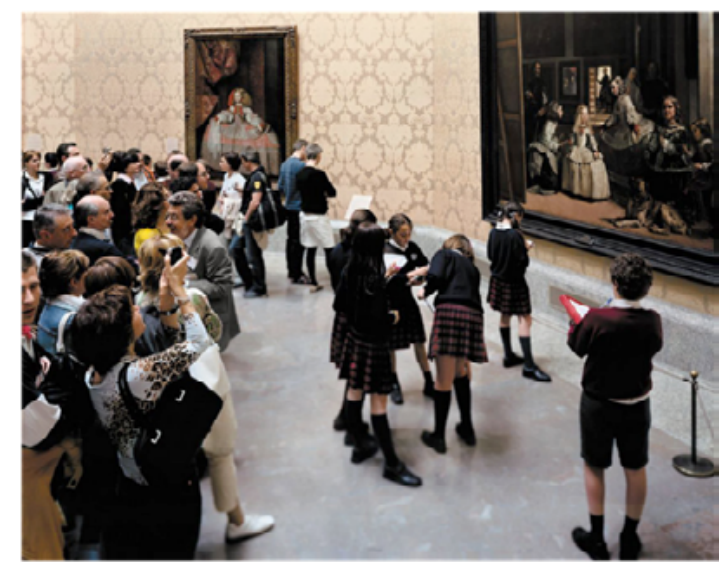

Figura 3: Meninas a ver Las Meninas no Museu do Prado

Thomas Struth, Museo del Prado 7 Madrid, 2005, c-print, $178 \times 219$ cm, 2008

Créditos: Thomas Struth

Do Museu do Prado ao Museu Picasso, entre mais digressões no tempo, no espaço e por imagens como as de Thomas Struth ou noutras iconoesferas (Bizri, Johnson \& Vasilakis, 1998)7, Las Meninas ainda podem viajar com mais formas/movimentos por espaços outdoors, imagéticos e físicos como nas Meninas de Manolo Valdés (n. 1942) com novos rostos e toucados, esculturas graciosas alinhadas no passeio público. Ou parte delas, as cabeças, que Valdez reinterpretou criativamente nas Damas, também inspiradas em Rembrandt, Zurbarán, Rubens ou Matisse ${ }^{9}$. Assim, as esculturas representam palimpsestos mnemónicos e imaginários com recurso a obras-primas na história da arte para sobre elas indagar e superar; tal como sobre Velázquez, para o lembrar e "esquecer"

Em Madrid existem quatro Damas, coroadas pela monumental La Dama del Manzanares (2003) em bronze e aço no topo do parque homónimo"', a que se juntam Meni-

\footnotetext{
${ }^{7} \mathrm{Na}$ iconosfera digital, com imagens recriativas à semelhança de outras obras-primas como se mostrou sobre Portrait of Giovanna degli Albizzi Tornabuoni (1489-1490) de Domenico Ghirlandaio (Barranha, 2018).

${ }^{8}$ Artista valenciano com projeção internacional, muito premiado desde 1965, um dos fundadores da Equipo Crónicas (19631981) com papel de relevo na renovação da pintura em Espanha.

9 Rembrandt van Rijn (1606 -1669); Francisco de Zurbarán (1598-1664); Peter Paul Rubens (1577-1640); Henri Matisse (1869-1954).

10 Título da exposição "Olvidando a Velázquez. Las Meninas", Museu Picasso, Barcelona, de 16 de maio a 28 de setembro de 2008, com 61 obras em pintura, escultura, fotografia, gravura, vídeo, com reflexo da influência de Velázquez.

"Parque Lineal del Manzanares em Madrid, em torno do rio homónimo. A escultura de Valdés aparece no topo do monte artificial de La Atalaya, mirador para a cidade, sobre una plataforma piramidal de 21 metros de altura, desenhada pelo arquitecto Ricardo Bofill. Desde 2005, iluminada por 24 projetores que mudam as tonalidades consoante as estações. As outras três Damas madrilenas, também de 2003, encontram-se no aeroporto de Barajas. Em 2005, Valdés realizou igualmente
} 
nas em circulação por praças e ruas de várias cidades. Resta saber se quem as encontra identifica a origem em Las Meninas. Identificando-a, a receção será capaz de comparar e perceber a metamorfose artística, mas sem esse recuo ao referente predomina o sentido em parte mutilado sobre as esculturas. Em Espanha, em cidades como Madrid, Córdova, Oviedo, Saragoça, San Sebastian, Valadollid e outras, muitos devem reconhecer Las Meninas nas obras de Valdez, conhecendo-as, porque o quadro de Velázquez integra o património nacional, escolar e visual.

O mesmo não acontece para a generalidade de turistas e habitantes em diferentes contextos, embora sem travar o aplauso para estas obras pela animação que trazem ao palco urbano. Entre mais perceções de esquivas a atentas às esculturas pela sua graciosidade e dimensão, suspensa fica a sua plena legibilidade, no entanto relativa e distinta do gosto para admirar as esculturas no espaço público. O ponto seguinte sistematiza mutações que aí ocorrem em vários planos.

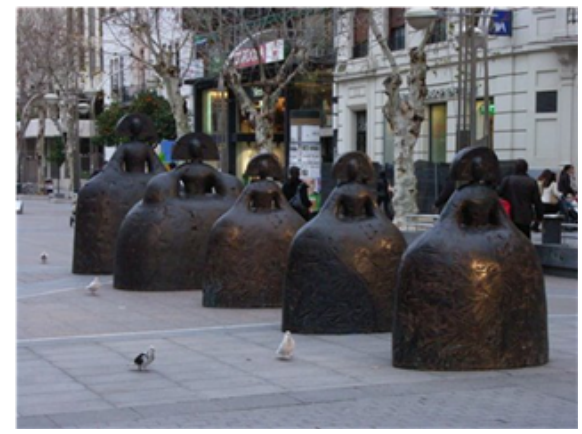

Figura 4: Meninas de Manolo Valdés numa rua de Córdova, 2010

Créditos: Idalina Conde e Fernando Ribeiro

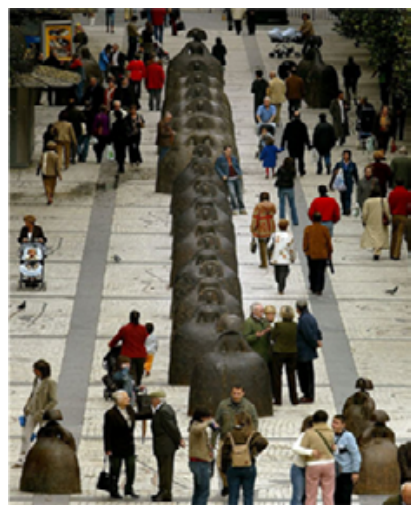

Figura 6: Meninas de Manolo Valdés em Oviedo, 2005 Fonte: https://www.minube.com/rincon/ oviedo-y-las-meninas-de-manolo-valdes-a2135218\#gallery-modal

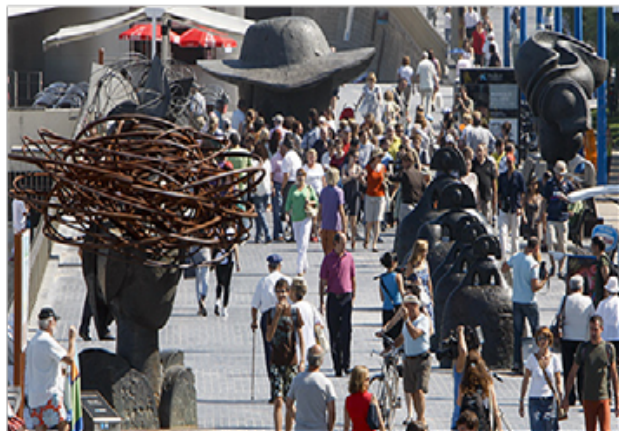

Figura 5: Meninas e Damas de Manolo Valdés em San Sebastian, 2009

Fonte: "San Sebastián convive con las esculturas de Manolo Valdés", 2009

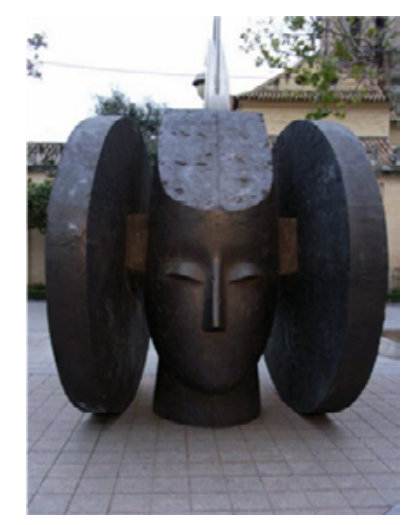

Figura 7: La Dama (2004) de Manolo Valdés numa rua de Córdova, 2010

Créditos: Idalina Conde e Fernando Ribeiro

dois cavalos, Asturcones, para a cidade de Oviedo e aí levou 21 esculturas de Meninas. 


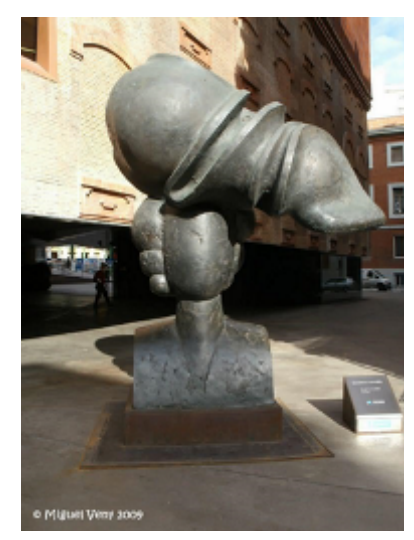

Figura 8: Regina II (2005) de Manolo Valdés, Paseo del Prado, Madrid, 2009

Créditos: Miguel Veny Torres

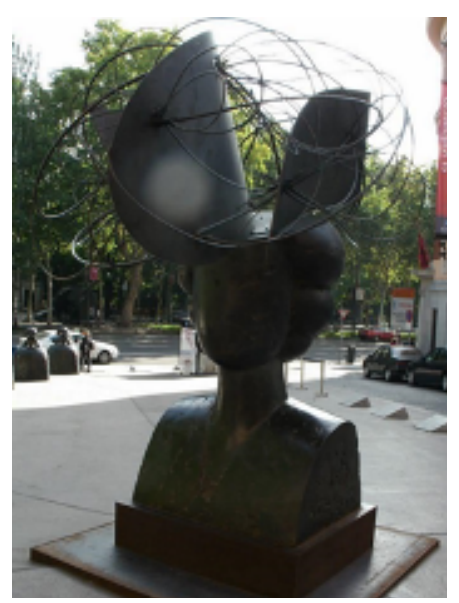

Figura 10: Regina II (2005) de Manolo Valdés, Paseo del Prado, Madrid, 2009

Créditos: Miguel Veny Torres

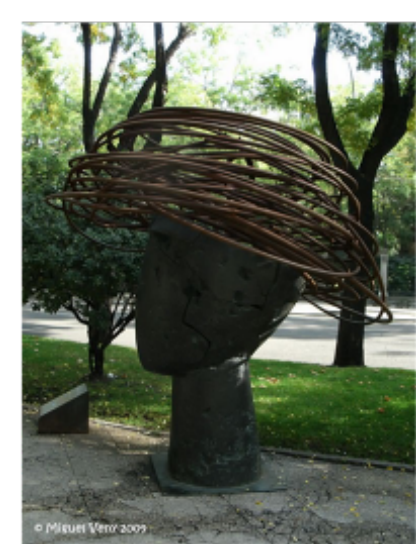

Figura 9: Ariadna IV (2004) de Manolo Valdés, Paseo del Prado, Madrid, 2009

Créditos: Miguel Veny Torres

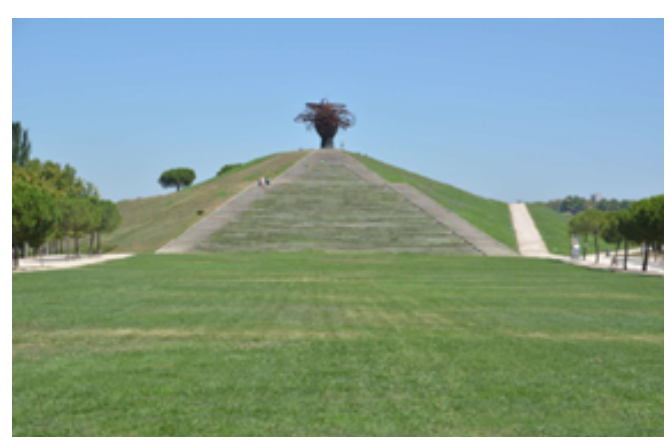

Figura 11: La Dama del Manzanares (2003)de Manolo Valdés, Parque Lineal del Manzanares, Madrid

Fonte: www.miradormadrid.com

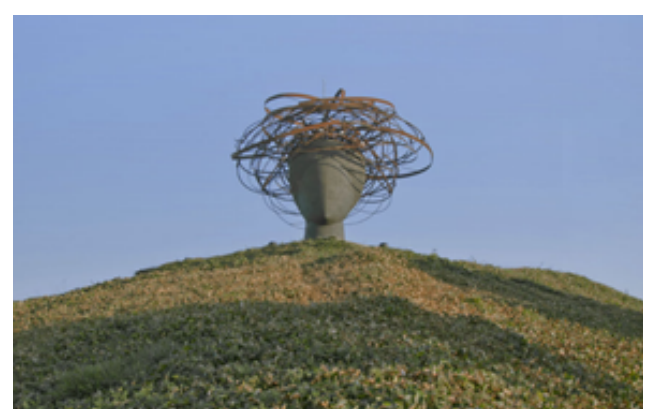

Figura 12: La Dama del Manzanares (2003) de Manolo Valdés, Parque Lineal del Manzanares, Madrid

Fonte: www.miradormadrid.com 


\section{MUTAÇÕES DE INDOORS PARA OUTDOORS}

Semiologicamente, a passagem da perceção a receção (Conde, 1992) implica o recurso mesmo se elementar ou interrogativo à "chave" de um código: o referente, por vezes com densa textura. Base para a reflexividade com que se elabora sentido e manifesta a opinião, substancialmente uma questão de literacia ou educação artística (Queiroz, 2017; Conde, no prelo). É paralela a outras formas de envolvimento emocional, lúdico, estético e estésico, ou sensorial com as obras de arte. Donde, de legibilidade e afeto também se fala sobre a visita a museus (Henning, 2007) e o espaço público incrementa alternativas à decifração de códigos. Mesmo porque aí nem todas as obras têm a semiologia de signos espessos (Conde, 2014C), muitas há decorativas, ideográficas, funcionais e lúdicas.

O museu, e contextos análogos, institucionaliza um modo de ver (Alpers, 1991) concentrado e contemplativo em contraste com o olhar panorâmico, digressivo, fugaz ou esquivo no espaço público. Enquanto que no museu operam mediações pedagógicas, como visitas guiadas ao serviço da legibilidade, o equivalente não funciona no exterior onde, de resto, muita arte pública se concebe para a experiência prática e direta. Sem mediações ou, pelo menos, daquele género. As exposições temporárias no espaço público correspondem a outra situação porque enquadram as obras com estratégias de comunicação e mediação simbólica (Davallon, 2000). Salvo isso, do ponto de vista cognitivo as obras em outdoors apresentam-se mais vulneráveis ao des/reconhecimento dos transeuntes.

Qual a portabilidade dos seus saberes escolares, periciais ou mediáticos (Saurier, 2008) para identificarem uma obra-prima, Las Meninas de Velasquez nas Meninas de Valdéz? Repete-se a questão da literacia da qual ainda depende a "alocação da atenção" (Coavoux, 2016) e muitas vezes influenciada pelo estatuto das obras. Contudo, nem tudo se resume ao saber. Há o gosto, a surpresa e o encanto como se depreende da atenção para as vistosas Damas e Meninas, ao invés de obras mais discretas ou adversas no espaço público. A atenção é fundamental na génese de qualquer processo de perceção versus receção, e sobretudo neste espaço que transforma a ecologia da atenção.

A expressão vem de ambientes digitais (Citton, 2014) com novos paradigmas do visual (Raux \& Dubuisson, 2015) e a scripted culture que atravessa - com a digitalização - a esfera pública e cultural (Widmer \& Kleesattel, 2018). Dos hipertextos, zapping ou surf pelo ciberespaço igualmente emergem problemas de atenção (Birkerts, 2015) que se acrescentam a suspensões da perceção, ou atenção, assinaladas na cultura visual e do espetáculo (Crary, 2000; Kennedy, 2009). Análogo, o espaço público físico constitui uma ecologia onde construir a atenção, e com passagem do olhar ao ver (Conde, 2015a), é o desafio contra a indiferença e uso fraco das obras/imagens (Ghebaur, 2013a; Passeron, 1991/2006; Pecqueux, 2003). Mesmo à ecologia atencional do museu não faltam tais "condutas sem crença e obras de arte sem espectadores" - citando o título de artigo sobre o assunto (Veyne, 1988). Então, bastantes obras encontram-se em modo menor de realidade (Piette, 2009) por não terem a devida atenção. 
Como observar a flutuação de alheamentos e interesses na não/receção? A etnometodologia visual, que se aplica in/outdoors entre mais etnografias (Gonon, 2007), é um recurso heurístico para "seguir percursos" (Mariani-Rousset, 2001/2008), práticas do olhar (Goodwin, 2001; Sturken \& Cartwright, 2001/2003), o engajamento corporal com as obras (Belting, 2014; Coavoux, 2015a), a duração e dinâmicas da atenção (Coavoux, 2015b). Aliás, vários dos tópicos aparecem em projetos artísticos que visam modos de atender, olhar, usar, interagir e participar; em suma, os comportamentos do espectador como enjeux da arte contemporânea (Viollet, 2011).

Quanto aos estudos sociológicos e afins, os tópicos alargam a perspetiva e deve-se ressalvar que a noção de não/públicos ganha recortes concetuais no espaço público, sem homologia linear com a não/receção ${ }^{12}$. Com efeito, aí a arte destina-se a cidadãos de que só uma parte exígua coincide com públicos de museus ou exposições. Classificar o vasto resto como não-públicos obscurece em dois planos. Quer porque não-públicos habituais de arte se relacionam com obras de arte pública pelo menos como espectadores; quer porque aquela classificação subtrai a problemática da cidadania inerente à arte no espaço público. A polissemia deste espaço (Barril, Carrel, Guerrero \& Marquez, 2003) solicita dimensões da esfera pública e, se isso importa para os museus (Barrett, 2011), mais se vincula com a publicness daquela arte (Andrade, 2010; Baldini, 2014).

As próprias - algumas - obras suscitam "micro" esferas públicas com o envolvimento de cidadãos. Exemplo nos diferendos célebres (Conde, 2004) e não apenas por questões estéticas que nem sempre têm a presumida prioridade (Hanquinet, 2018). Os argumentos em causa, que se reencontram em desentendimentos mais comuns, esgrimem valores para além do belo e do feio (Heinich, Schaeffer \& Talon-Hugon, 2014). Cívicos, éticos, políticos, económicos, jurídicos, urbanísticos, ecológicos, etc., são valores que se mobilizam na construção de opinião pública. Ao mesmo tempo que as relações da arte contemporânea com a cidadania decorrem multifacetadas, desde com a ergonomia sociocultural em grande parte da arte pública a projetos de estética relacional, site-specific, comunitários e emancipatórios.

Em síntese, temos tanto "zonas de contacto" como disputas na esfera pública com diversidade de culturas e arte (Conde, 2010a, 2010b). Provocação e dialogismo é o binómio que também se retira de um ensaio sobre pedagogia do teatro (Desgranges, 2006). As tensões podem eclodir em situações específicas, ou advir de "artes da perturbação" (Mahiou \& Riado, 2014), mormente na frente mais crítica, política e "artivista" com lastro desde vanguardas nos anos 1970 e o impulso nos anos 1990 (Conde, 2003, 2009; Moner, 2012). Cruzada com viragens da desconstrução e do pós-colonial, entre outras, esta frente subverte a ideologia de joy forever na moda da criatividade e produz signos espessos, donde exigentes na comunicação com a receção. É a referência para introduzir o segundo exemplo em contraponto com as Meninas.

\footnotetext{
${ }^{12} \mathrm{O}$ alargamento de perspetiva refere-se a aspetos menos frequentes em abordagens de públicos ou audiências. Igualmente importa a problematização da noção de não-públicos (Ancel \& Pessin, 2004; Ghebaur, 2017; "Public, non-public: questions de méthodologie", 2017).
} 


\section{Contraponto com Circle of Animals}

Temos, então, Ai Weiwei (1957-), artista no vértice da arte contemporânea e global, opositor ao regime político na China de que foi vítima, ativista pelos direitos humanos, e criador infatigável de mega instalações ou exposições ${ }^{13}$. Naquela linha, e da estética relacional a maior escala, Farytale foi o projeto com que Weiwei levou 1001 chineses à Documenta 12 de Kassel, em 2007, assim como igual número de antigas cadeiras chinesas, património da era pré-comunista (“Documenta Kassel 18/06 - 23/09", 2007; Schnetz \& Weiwei, 2013). Uma escultura humana em campo (muito) expandido (Krauss, 1979) para trazer o Oriente ao Ocidente por via desta arte de compromisso político (Moner, 2009, 2015).

Farytale pertence ao tríptico das maiores instalações ao ar livre em Kassel nesse ano'4. No entanto, falando no texto em cabeças como as de Damas e Meninas, revisitamos outra obra de Weiwei: Zodiac Heads/Circle of Animals (2010-2011), conjunto de esculturas em bronze com a figuração das 12 criaturas do zodíaco chinês que também viajaram entre países e de indoors para outdoors (Delson \& Weiwei, 2011). Consistiu no primeiro grande projeto de escultura pública do artista para uma digressão nos Estados Unidos, Europa e Ásia. Em 2010 também estiveram na 29 ${ }^{a}$ Bienal de S. Paulo. A seguir rumaram para Nova lorque em 2011, onde se instalaram na histórica Pulitzer Fountain's da Grand Army Plaza em Manhattan, ao sul do Central Park.

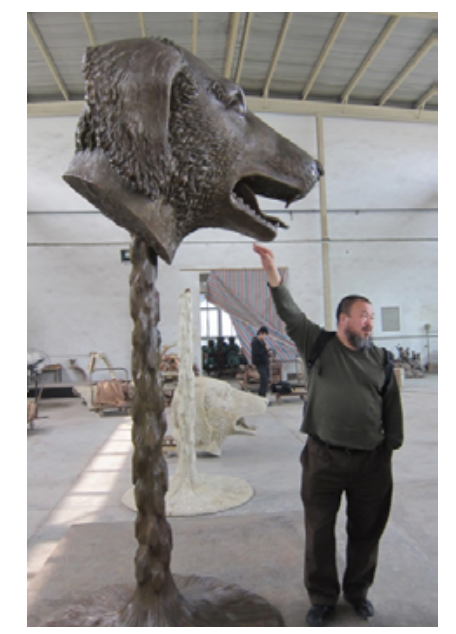

Figura 13: Ai Weiwei ao início do processo, na fundição em Chengdu, China

Fonte: www.zodiacheads.com

\footnotetext{
${ }_{13}$ Sobre o artista ver algumas referências na bibliografia (Gaensheimer, Krystof \& Wolf, 2019; Sorace, 2014; Weiwei \& Holzwarth, 2016).

${ }^{14}$ As outras duas foram Terrace Rice Field de Sakarin Krue-On e Mohnfeld/Poppy Field de Sanja Ivekovic ("Documenta Kassel 18/06 - 23/09", 2007; Conde, 2009, 2014b).

${ }^{15}$ Inaugurada em 1916, a fonte deve-se a Joseph Pulitzer (1847-1911), figura da imprensa e do partido democrático. Também ajudou a trazer a Estátua da Liberdade para Nova Iorque.
} 


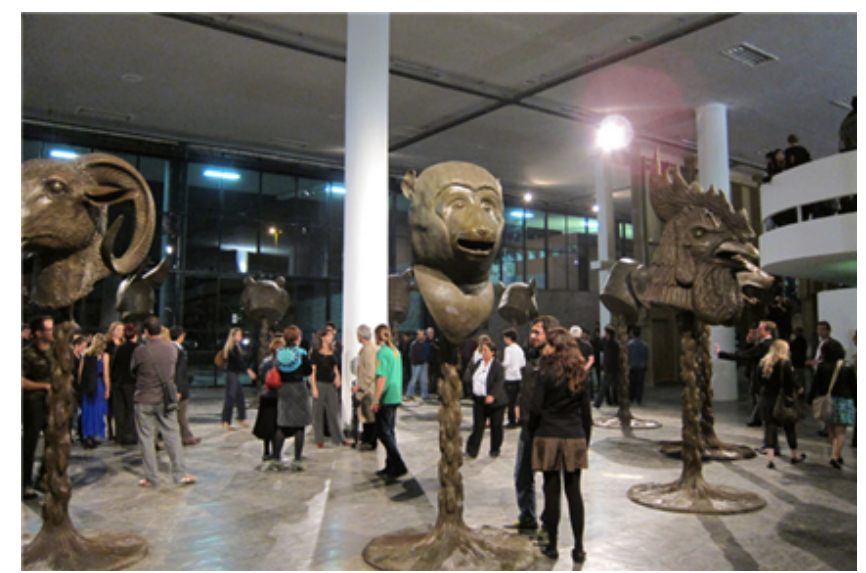

Figura 14: Ai Weiwei, Zodiac Heads/Circle of Animals de Ai Weiwei, série em bronze $29^{\text {a }}$ Bienal de S. Paulo, 2010

Fonte: www.zodiacheads.com

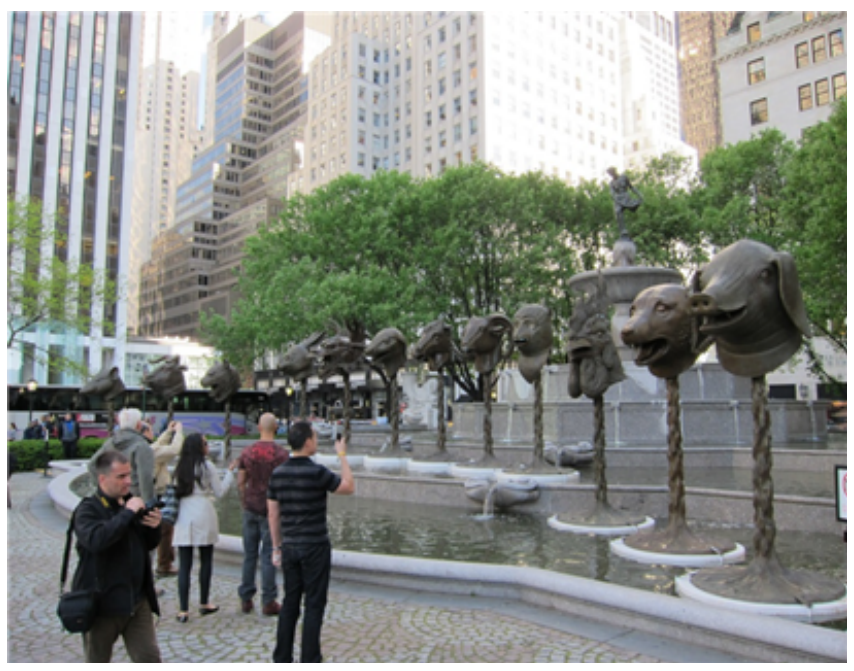

Figura 15: Circle of Animals/Zodiac Heads de Ai Weiwei na Pulitzer Fountain Grand Army Plaza (Central Park), Nova lorque, 2011

Fonte: arrestedmotion.com

Após S. Paulo e Nova Iorque, Circle of Animals circulou por mais 23 cidades nos Estados Unidos, Europa, Taiwan. A Bronze Series duplica-se na Gold Series, bronzes com patine dourada. Entre 2012 e 2019, viajaram por 19 locais no Canadá, Estados Unidos, Rússia e Austrália ${ }^{16}$. A imagem abaixo mostra uma passagem desta série portátil por Marselha.

${ }_{16}$ Retirado de http://www.zodiacheads.com/world_tour_bronze.html e http://www.zodiacheads.com/world_tour_gold. html 


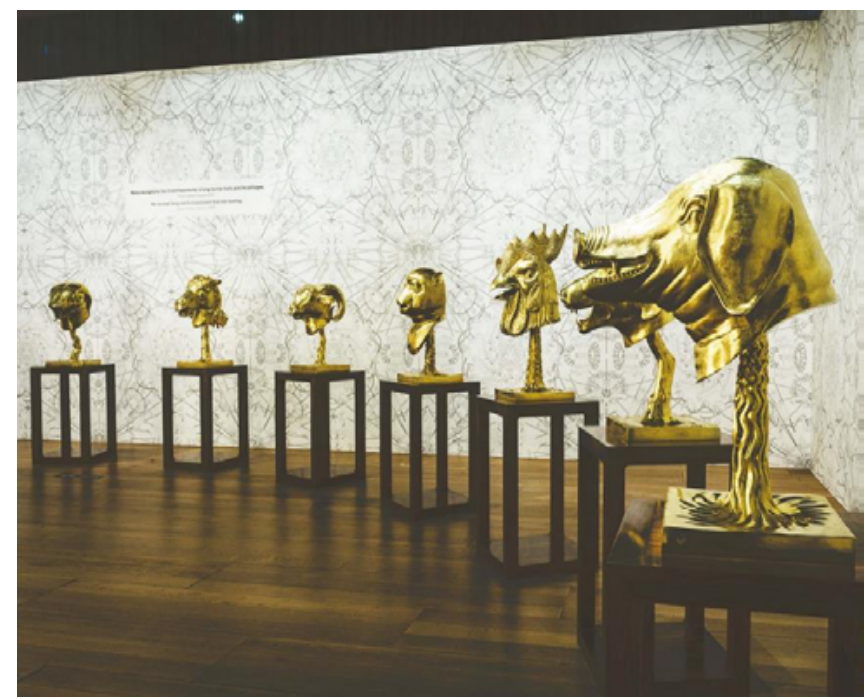

Figura 16: Circle of Animals/Zodiac Heads, Gold Series, na exposição Ai Weiwei Fan-Tan, 20 junho - 12 novembro, 2018, MUCEM - Musée des Civilisations de l'Europe et de la Méditerranée, Marselha

Créditos : MUCEM

Quanto à semiologia das cabeças e possíveis transformações possíveis no seu périplo por diferentes ambientes e audiências, para quem conhece o trabalho de Ai Weiwei saberia tratar-se de um signo espesso e político com o confronto do Oriente com o Ocidente. Concretamente, a China antiga ou anterior ao regime comunista que regressa às obras de Weiwei. Ele diz: "nunca mudamos o assunto mas sempre a interpretação" (Ai Weiwei, 2013) ${ }^{17}$, e neste caso para contar uma história de violência da Europa sobre a China, com saque e humilhação.

Circle of Animals ${ }^{18}$ mostra réplicas do zodíaco criado no século XVIII por jesuítas europeus ${ }^{19}$ na corte do Imperador Qianlong da dinastia Qing. Originalmente decoravam uma fonte-relógio de água nos jardins de Yuanmingyuan, Antigo Palácio de Verão do Imperador, perto de Pequim. Em 1860, no desfecho da Segunda Guerra do Ópio (18561860), as tropas francesas e britânicas destruíram e saquearam o magnífico Yuanmingyuan - mais do que um palácio, um complexo de edifícios e jardins ${ }^{20}$. Um episódio bárbaro pelo qual aportou na Europa um tesouro de arte chinesa, objetos e as cabeças da fonte, embora feitas por jesuítas europeus, conotam-se com a ferida nacional (Kleutghen, 2011; Lee, 2012; Ringmar, 2013a; Thomas, 2008).

\footnotetext{
17 Afirmação consultada em "Ai Weiwei: Zodiac Heads", https://www.youtube.com/ watch?time_continue $=65 \& v=u 1 f \_H m o T 7 b M \&$ feature $=$ emb_title

${ }^{18}$ Retirado de http://www.zodiacheads.com/about_exhibit.html

${ }^{19}$ Giuseppe Castiglione (1688-1766), pintor, e Michel Benoist (1715-1774), responsável pelo sistema hidráulico e fontes em Yuanmingyuan, dois entre mais jesuítas com presença na China e encontros interculturais no século XVIII (Kleutghen, 2012, 2015; Musillo, 2011; Siu, 1988; Vossilla, 2016).

${ }^{20}$ No entanto, só as tropas britânicas incendiarem Yuanmingyuan. Após a destruição, o espaço em ruínas teve uma história atribulada de abandono e resgate, a certo momento, com a ideia do governo chinês em o transformar num parque temático que representaria outra forma de "visão imperial" (Ringmar, 2013b).
} 
Esta ambivalência simbólica estimulou $\mathrm{Ai}$ Weiwei ${ }^{21}$ que reinterpretou as cabeças em grande escala, incluindo imaginar alguns exemplares desaparecidos, e produziu o signo duplamente espesso. Por um lado, contém a trama de encontros/embates entre civilizações, a violência dos saques, nacionalismo e repatriação patrimonial. Por outro lado, signo que continua o questionamento do artista sobre noções do falso e cópia face a um original, ou suposto como tal. Como foi o signo re/conhecido?

Recuando ao início, ao indoors da Bienal de S. Paulo com a maioria de públicos de pares e informados (similares a visitantes da Documenta em Kassel), haveria o horizonte de expectativa para esta obra e a sua mensagem. Em geral, um público com referências e sobre Weiwei. Além disso, hábil a lidar com armadilhas semióticas com base na literacia artística para capturar sentidos densos sob a superfície visual das obras. Neste caso também com a sinapse entre a memória de uma violência no século XIX e a denúncia de atribulações contemporâneas. Já quanto a Nova lorque, com Circle of Animals em outdoors, salvo para o segmento idêntico de artistas e aficionados de Ai Weiwei, as expectativas nem existiriam para a vaga de cidadãos que atravessam a Grand Army Plaza.

$\mathrm{Na}$ diversidade de situações, a alguns dos menos avisados enganaria o próprio naturalismo das esculturas. Reféns da ilusão óptica de apenas reconhecer o familiar nestas Zodiac Heads: figuras do horóscopo chinês que se consulta sobre a personalidade, amor, fortuna, e futuro. Contudo, para se perguntar como poderiam tantos nova-iorquinos saber da história de Yuanmingyuan, opacidade inevitável na deslocação transtemporal e cultural destas obras. Embora o seu impacto dependa de circunstâncias que despertam a atenção com a pedagogia da curiosidade (Bann, 2008; Thomas, 2016) para procurar informação. Ou por razões cívicas, como no caso. Recorde-se que a inauguração de Circle of Animals em Nova lorque, em maio de 2011, coincidiu com a prisão de Weiwei ${ }^{22}$, transformando-se num evento altamente político.

Frente à Pulitzer Fountain discursaram autoridades, notáveis, associações de artistas e intelectuais clamando pela libertação do artista. A própria diplomacia dos Estados Unidos mobilizou-se junto das autoridades chinesas e, com a mediatização do caso, menos seriam os indiferentes à obra na Grand Army Plaza, capazes de lhe acrescentar uma interpretação livre e solidária com Ai Weiwei. Animals como cabeças antropomórficas dos "animais" que o prenderam: o porco, o cão, o galo, líderes do regime chinês. Assim, mais uma curva na sinuosa semiose (Véron, 1981) da arte em público com as suas tantas viagens.

\footnotetext{
${ }^{21}$ Circle of Animals parte da controvérsia em 2009, com surto nacionalista. Nesse ano reapareceram no leilão da Christie's as cabeças de um rato e um coelho do zodíaco original, propriedade da coleção de Yves Saint Laurent e Pierre Bergé. A China tentou impedir legalmente o leilão que, no entanto, se realizou e o licitador chinês Cai Mingchao, art dealer e consultor do Fundo de Tesouros Nacionais (fundação para aquisição de arte chinesa pelo mundo) arrebatou as peças por quase 40 milhões de dólares (14 milhões de euros por cada cabeça) para as retirar do mercado internacional e devolver à pátria. Recusou-se a pagar a quantia à Christie's, as peças voltaram à coleção da Fundação Pierre Bergé - Yves Saint Laurent e, posteriormente, o magnata e colecionador François Pinault comprou-as para, disse, as devolver à China. Em 2009, o também magnata Sanley Ho adquiriu a cabeça do cavalo por milhões para retorno à China e uma cabeça de javali, comprada em venda privada. Na posse do Museu Politécnico de Pequim, já com mais duas cabeças, do macaco e do boi.

22 Ver http://arrestedmotion.com/2011/05/openings-ai-weiwei-circle-of-animals-zodiac-heads-pulitzer-fountain-central-park. Weiwei foi detido a 3 de abril de 2011 no Aeroporto Internacional de Pequim, pouco antes de viajar para Hong Kong.
} 


\section{OBSERVAÇÕes FINAIS}

Entre o que querem as imagens (Mitchell, 2006) e o que delas querem pessoas, ou que querem da arte (Arts Council of England, 2008) existe a clivagem de perspetivas que vão do âmbito estético e iconológico ao sociológico. Alternativamente, o texto traz uma abordagem eclética que contraria absolutos ou pressupostos sobre o "querer". Em primeiro lugar, porque contra o "essencialismo visual" (Bal, 2005), boa parte da arte em público compreende puzzles semióticos (Elkins, 1999) que não nos pedem apenas o "compromisso para olhar" (Bal, 2003). Mais do que as ver, ter com elas uma relação pelo seu uso e outros envolvimentos. A digressão das obras também altera os quadros da sua visitabilidade, visualidade e legibilidade. Em segundo lugar, quanto ao que as pessoas querem, ou não, depende de condições socio-culturais e circunstâncias; da especificidade de espaços in/outoors. E, ainda, de "modos de expectar" (Oddey \& White, 2009) induzidos pela culture on display e em touring como produção contemporânea da visitabilidade (Dicks, 2003) que interfere no querer.

Eis o enredo para a abordagem no texto que extravasa referências habituais na sociologia de públicos e políticas de emancipação, pense-se em Pierre Bourdieu e legados ou em Jacques Rancière (Nordmann, 2006; Rancière, 2008). Há mais a dizer e com a problemática da mobilidade também como um traveling concept (Neumann \& Nunning, 2012) em cruzamento no texto com os conceitos de receção e literacia em movimento. A itinerância da arte proporciona diversos regimes de experiência em micro (Roueff, 2011) e macro escalas, locais e globais, físicas e virtuais. Por conseguinte, com relevo para os modos de comunicação com públicos e o espaço público, paralelamente à comunicação pública de instituições como os museus (Andrade, 2015). Em suma, um conjunto de fatores para promover encontros com as obras: experimentar, praticar, ensinar (Chabanne, Parayre \& Villagordo, 2012).

Relativamente aos exemplos no texto, esse ensinar ainda se aplica à literacia histórica e europeia. Ou melhor, sobre a Europa em interface com o mundo, linha que o texto comunga ${ }^{23}$. Las Meninas de Velazques representam uma grande referência europeia a que as suas recriações e viagens acrescentam dimensões globais. De resto, dimensões que perpassam bastante do património na Europa (Conde, 2019a). Circle of Animals recorda parte da violência nas relações com o mundo, um episódio da Europa sobre a China. Concluindo, viagens da arte para atualizar o "Atlas de imagens" warburgiano ${ }^{24} \mathrm{e}$ com mais casos sobre a história global da Europa. Paralelamente à história da arte que agora também se reescreve sobre as infindáveis circulações artísticas (Kaufmann, Dos$\sin \&$ Joyeux-Prunel, 2015).

\footnotetext{
${ }^{23}$ Em diálogos com imagens que revisitam diversas referências (Conde, 2015a, 2015b); sobre relações presenciais e virtuais dos cidadãos na União Europeia como património e a análise do portal Europeana para o património digital, arte e lembrança (Conde, 2019b).

${ }^{24}$ Referência ao "Atlas Mnemosyne" de Aby Warburg (1866-1929), construído com símbolos e arquétipos transtemporais em que as imagens emblematizam a memória, metáfora e alegoria (Johnson, 2012).
} 


\section{REFERÊNCIAS}

Abreu, J. G. \& Castro, L. (Eds.) (2017). Arte pública na era da criatividade digital. Atas do colóquio internacional. Porto: Universidade Católica Editora.

Alpers, S. (1991). The museum as a way of seeing. In I. Karp \& D. S. Lavine (Eds.), Exhibiting cultures: the poetics and politics of museum display (pp. 25-32). Washington: Smithsonian Institution Press.

Ancel, P. \& Pessin, A. (Eds.) (2004). Les non publics. Les arts en réception. Paris: L' Harmattan.

Ancell, M. (2013). The theology of painting: picturing philosophy in Velázquez's Las Meninas. The Comparatist, $37(1), 156-168$.

Andrade, P. (Ed.) (2010). Arte pública e cidadania: novas leituras da cidade criativa. Lisboa: Caleidoscópio.

Andrade, P. (2015). Comunicação pública da arte: o caso dos museus de arte locais /globais. Lisboa: Edições Caleidoscópio.

Arts Council of England (2008). What people want from the arts. Londres: Arts Council of England. Retirado de https://webarchive.nationalarchives.gov.uk/20160204122832/http://www.artscouncil.org.uk/ advice-and-guidance/browse-advice-and-guidance/what-people-want-from-the-arts

Athanassopoulos V. \& Mahiou, C. (2012). L'art et l'espace public. Revue Proteus. Cahiers des Théories de l'Art, 3. Retirado de http://www.revue-proteus.com/Proteuso3.pdf

Bal, M. \& Hernández-Navarro, M. Á. (Eds.) (2011). Art and visibility in migratory culture: conflict, resistance, and agency. Amesterdão: Rodopi.

Bal, M. (2003). Visual essentialism and the object of visual culture. Journal of Visual Culture, 2(1), 5-32.

Bal, M. (2005). The commitment to look. Journal of Visual Culture, 4(2), 145-162.

Baldini, A. (2014). Public art: a critical approach. Tese de doutoramento, Temple University, Filadélfia, EUA.

Bann, S. (2008). The return to curiosity: shifting paradigms in contemporary museum display. In A. McClellan (Ed.), Art and its publics. Museum studies at the millennium (pp. 117-132). Malden, Oxford, Reino Unido: Blackwell.

Barranha, H. (2018). Derivative narratives: the multiple lives of a masterpiece on the internet. Museum International, 70(1-2), 22-33.

Barrett, J. (2011). Museums and the public sphere. Chichester: Wiley-Blackwood.

Barril, C., Carrel, M., Guerrero, J.-C. \& Marquez, A. (Eds.) (2003). Le public en action. usages et limites de la notion d' espace public en sciences sociales. Paris: L'Harmattan.

Barthes, R. (1980). La chambre claire. Note sur la photographie. Paris: Seuil.

Belting, H. (2014). An anthropology of images: picture, medium, body. Princeton: Princeton University Press.

Birkerts, S. (2015). Changing the subject. Art and attention in the internet age. Minneapolis: Graywolf Press.

Bizri, H., Johnson, A. \& Vasilakis, C. (1998). Las Meninas in VR. Storytelling and the illusion in art. In J.-C. Heudin(Ed.), Virtual Worlds. Conference (pp. 360-372). Paris: Springer.

Caeiro, M. (2014). Arte na cidade. História contemporânea. Lisboa: Temas e Debates. 
Calvário, F. (2008). Sentidos da arte pública. Reflexão sobre os significados da arte pública em periferias urbanas: Almada e Parque das Nações. Dissertação de Mestrado, Instituto Superior Técnico, Lisboa, Portugal.

Calvário, F. (2009). A arte pública como acontecimento urbano - centro e periferia. On the W@terfront, The On-line Magazine on Waterfronts, Public Space, Public Art and Urban Regeneration, 12, 67-79.

Chabanne, J.-C., Parayre, M. \& Villagordo, E. (Eds.) (2012). La Rencontre avec l' œuvre. Eprouver, pratiquer, enseigner les arts et la culture. Paris: L'Harmattan.

Citton, Y. (Ed.) (2014). Pour une écologie de l'attention. Paris: Seuil.

Coavoux, S. (2015a). L'engagement corporel des visiteurs de musée. In L. Jacquot, L. \& J.-M. Leveratto (Eds.), Relire Durkheim et Mauss. Émotions: religions, arts et politiques (pp. 187-201). Nancy: Presses Universitaires de Nancy.

Coavoux, S. (2015b). De la mesure du temps à l'analyse des séquences d'action. Dynamique de l'attention dans les études du public des musées. Nouvelles Perspectives en Sciences Sociales, 10(2), 237-271.

Coavoux, S. (2016). Reconnaître un chef-d'oeuvre. L'influence du statut d'une œuvre dans l'allocation de l'attention des visiteurs au musée d'art. Regards Sociologiques, 48, 23-36.

Conde, I. (1992). Perceção estética e públicos da cultura: perplexidade e redundância. In I. Conde (Ed.), Percepção estética e públicos da cultura (pp. 143-167). Lisboa: ACARTE/Fundação Calouste Gulbenkian.

Conde, I. (2003). Desordem e arte contra a cultura. In J. Rebelo (Ed.), Novas formas de mobilização popular (pp. 271-286). Porto: Campo das Letras.

Conde, I. (2004). Desentendimento revisitado. In Santos, M.L.S. (Ed.), Públicos da cultura (pp. 173-197). Lisboa: Observatório das Atividades Culturais.

Conde, I. (2009). Arte e poder. CIES Working-Papers, 62, 1-36.

Conde, I. (2010a). Contrasting narratives: art and culture in the public sphere. In P. Ahonen, H. Sakari \& K. Palonen (Eds.), Fortunae rota volvitur: studies on the writings and other work of Ilkka Heiskanen (pp. 276287). Helsínquia: The Finnish Political Association.

Conde, I. (2010b). Arte, cultura, criatividade: diferentes narrativas. In M. L. L. Santos \& J. M. Pais (Eds.), Novos trilhos culturais: políticas e práticas (pp. 121-134). Lisboa: Imprensa de Ciências Sociais.

Conde, I. (2014a). Reconhecimento em arte: passagens de um percurso. Tese de Doutoramento, Instituto Universitário de Lisboa, ISCTE-IUL, Lisboa, Portugal.

Conde, I. (2014b). Art and power: contemporary figurations. In F. McIntosh-Varjabédian \& M.-M Castellani (Eds.), Représenter le pouvoir. Images du pouvoir dans la littérature et les arts (pp. 375-392). Bruxelas: P.I.E. Peter Lang.

Conde, I. (2014C). Valor e valores num signo espesso. In P. Mendes \& S. V. Jürgens (Eds.), Collecting collections and concepts: uma viagem iconoclasta por colecções de coisas em forma de assim (pp. 496-491). Guimarães: Guimarães 2012 Capital Europeia da Cultura.

Conde, I. (2015a, março). Construire l'attention: art, littéracie et la contribution des musées. Comunicação apresentada na Conferência Perché Trasmettere la Conoscenza Artistica? / Pourquoi Transmettre la Connaissance des Arts?[ il contributo dei musei] [la contribution des musées]), Institut Français, Florença.

Conde, I. (2015b, abril). European iconographies for cultural literacy. Comunicação apresentada na First International Conference Cultural Literacy In Europe, Birkbeck Institute for the Humanities, Londres. 
Conde, I. (2015c, outubro). Arte em público: imagens para o debate sobre públicos e arte em espaços públicos. Comunicação apresentada no Encontro-debate Arte em Lugares Públicos: Arte e Públicos, Câmara Municipal de Lisboa, Café Império, Lisboa.

Conde, I. (2018, novembro). Mobilidade cultural em agendas europeias. Comunicação apresentada no Seminário Internacional Viver em|a Mobilidade: (Com)Passos, Rumos e Políticas, Évora.

Conde, I. (2019a, fevereiro). Europe and cultural heritage at large: recalling the global dimensions. Comunicação apresentada na Conferência Internacional Worlds of Cultural Heritage(s): History and Politics, Universidade de Coimbra, Coimbra.

Conde, I. (2019b, junho). Europeana: looking at a screen on cultural heritage, art and remembrance. Comunicação apresentada na Conferência International Visual Semantics. Visualizing Global Networks, Circulations, and Patterns, École Normale Supérieure, Paris.

Conde, I. (no prelo). Aprender com Leonardo: literacia para arte, cultura e Europa. Provas de Agregação Académica. Lisboa: Instituto Universitário de Lisboa.

Crary, J. (2000). Suspensions of perception: attention, spectacle and modern culture. Cambridge, Mass.: The MIT Press.

Davallon, J. (2000). L'Exposition à l'oeuvre: stratégies de communication et médiation symbolique. Paris: L'Harmattan.

Delroche, B. (2001). Le musée virtuel. Vers une éthique des nouvelles images. Paris: PUF.

Delson, S. \& Weiwei, A. (Eds.) (2011). Ai Wei Wei: Circle of Animals. Zurique: Jrp Ringier/Prestel.

Desgranges, F. (2006). Pedagogia do teatro: provocação e dialogismo. São Paulo: Hucitec.

Dicks, B. (2003). Culture on display. The production of contemporary visitability. Maidenhead: Open University Press.

Documenta Kassel 18/06 - 23/09 (2007). Catálogo. Kassel: Documenta Editions.

Eco, U. (2004/1990). Os limites da interpretação. Lisboa: Difel.

Elkins, J. (1999). Why are our pictures puzzles? On the modern origins of pictorial complexity. Nova lorque, Londres: Routledge.

Finkelpearl, T. (2001). Dialogues in public art. Cambridge, Massachusetts: The MIT Press.

Foucault, M. (1966/1981). As palavras e as coisas. São Paulo: Martins Fontes.

Fróis, J. P. (Ed.) (2001). Educação estética e artística. Abordagens transdisciplinares. Lisboa: Fundação Calouste Gulbenkian.

Fróis, J. P. (2008). Os museus de arte e a educação. Discursos e práticas contemporâneas. Museologia.pt, 2, $62-75$.

Gaensheimer, S., Krystof, D. \& Wolf, F. (Eds.) (2019). Ai Weiwei. Nova lorque: Prestel.

Goffman, E. (1974). Frame analysis. An essay on the organization of experience. Nova lorque: Harper and Row Torchbooks.

Chebaur, C. (2013). “Mais... je ne visite pas!”. Une approche ethnographique de l'usage faible des œuvres. Ethnologie Française, 43(4), 709-722. 
Chebaur, C. (2017). Enquêter sur les non-publics de la culture: quelle posture de recherche pour quel dispositif méthodologique. Interrogations. Revue Pluridisciplinaire de Sciences Humaines et Sociales, 24.

Cheorghe, C. (2010). Theories and uses in common: responses of art in the public sphere. Meta. Research in Hermeneutics, Phenomenology, and Pratical Philosophy, 2(2), 316-327.

Gonon, A. (2007). Ethnographie du spectateur. Le théâtre de rue pour prisme. Tese de Doutoramento, Universidade de Borgonha, Borgonha, França.

Goodwin, C. (2001). Practices of seeing visual analysis: an ethnometodological approach. In T. van Leeuwen \& C. Jewitt (Eds.), Handbook of visual analysis (pp. 157-182). Londres: Sage.

Gugleta, Z. (2011). Michel Foucault's (mis) interpretation of Las Meninas. Or, pure representation as the tautologous structure of the sign. Facta Universitatis Series: Linguistics and Literature, 9(1), 1-12.

Hamann, B. E. (2010). The mirrors of Las Meninas: cochineal, silver, and clay. The Art Bulletin, 92(1-2), 6-35.

Hanquinet, L. (2018). 'But is it good?' Why aesthetic values matter in sociological accounts of tastes. Journal of Cultural Analysis and Social Change, 3(2), 9.

Heinich, N., Schaeffer, J.-M. \& Talon-Hugon, C. (Eds.) (2014). Par-delà le beau et le laid. Enquêtes sur les valeurs de l'art. Rennes: Presses Universitaires de Rennes.

Henning, M. (2007). Legibility and affect: museums as new media. In P. Basu \& S. Macdonald (Eds.), Exhibition experiments. Ethnography, art, and science (pp. 25-47). Oxford: Blackwell.

Jiménez-Blanco, M. D. (2008). Picasso y la historia. El caso de Las Meninas. Anales de Historia del Arte, [vol. especial], $527-534$

Johnson, C. D. (2012). Memory, metaphor, and Aby Warburg's atlas of images. Ithaca, Nova lorque: Cornell University Press.

Kaufmann, T. D. C., Dossin, C. \& Joyeux-Prunel, B. (Eds.) (2015). Circulations in the global history of art. Farnham: Ashgate.

Kennedy, D. (2009). The spectator and the spectacle: audiences in modernity and postmodernity. Cambridge: Cambridge University Press.

Kleutghen, K. (2011). Heads of State: looting, nationalism, and repatriation of the Zodiac Bronzes. In S. Delson \& A. Weiwei (Eds.), Ai Wei Wei: Circle of Animals (pp. 162-183). Zurique: Jrp Ringier/Prestel.

Kleutghen, K. (2012). Staging Europe: theatricality and painting at the Chinese imperial court. Studies in Eighteenth-Century Culture, 42, 81-102.

Kleutghen, K. (2015). Imperial illusions: crossing pictorial boundaries in eighteenth-century China. Seattle: University of Washington Press.

Krauss, R. (1979). Sculpture in the expanded field. October, 8, 30-44.

Lacy, S. (1994). Debated territory: toward a critical language for public art. In S. Lacy (Ed.), Mapping the terrain. New genre public art (pp. 171-185). Seattle: Bay Press.

Lee, $\mathrm{H}$. (2012). The ruins of Yuanmingyuan: or, how to enjoy a national wound. In M. A. Matten (Ed.), Places of memory in modern China. History, politics, and identity (pp. 193-231). Leiden, Boston: Brill. 
Liljegren, D. (2012). Double exposure: multiplexing of signals and time in the photography of Thomas Struth. Shift - Graduate Journal of Visual and Material Culture, 5. Retirado de http://shiftjournal.org/wp-content/ uploads/2014/11/liljegren.pdf

Lucero, G. (2010). Picasso alquimista: una lectura de Las Meninas. Aisthesis, 47, 261-271.

Mahiou, C. \& Riado, B. (Eds.) (2014). Arts de la perturbation. Revue Proteus. Cahiers des Théories de l'Art, 7. Retirado de http://www.revue-proteus.com/Proteus07.pdf

Malraux, A. (1965/1997). Le Musée imaginaire. Paris: Gallimard.

Mariani-Rousset, S. (2001/2008). Espace public et publics d'expositions. Les parcours: une affaire à suivre. In M. Grosjean \& J.-P. Thibaud (Eds.), Espace urbain en méthodes (pp. 29-44). Marselha: Éditions Parenthèses.

McShine, K. (Ed.) (1999). The museum as muse: artists reflect. Nova lorque: The Museum of Modern Art.

Mitchell, W. J. T. (1994). Picture theory. Essays on verbal and visual representation. Chicago: University of Chicago Press.

Mitchell, W. J. T. (2006). What do pictures want? The lives and loves of images. Chicago: Chicago University Press.

Museo Nacional del Prado (2013). Velázquez y La Familia de Felipe IV [1650-1680]. Madrid: Museo Nacional del Prado.

Grønstad, A. \& Vågnes, Ø. (2006). An interview with W. J. T. Mitchell. Image Q Narrative, 15. Retirado de http://www.imageandnarrative.be/inarchive/iconoclasm/gronstad_vagnes.htm

Moner, L. M. (2009). El arte de acción en China: la producción artística como compromiso. Inter Asia Papers, 9, 1-36.

Moner, L. M. (2012). Migración, prácticas artísticas y artivismos. Polissema. Revista de Letras do Instituto Superior de Contabilidade e Administração do Porto, 12, 181-197.

Moner, L. M. (2015). Ai Weiwei: la recepción de su producción artística. Arte, Individuo y Sociedad, 27(3), $411-426$.

Musillo, M. (2011). Mid-Qing arts and Jesuit visions: encounters and exchanges in eighteenth century Beijing. In S. Delson \& A. Weiwei (Eds.), Ai Wei Wei: Circle of Animals (pp. 146-161). Zurique, MuniqueLondres, Nova lorque: Jrp Ringier/Prestel.

Neumann, B. \& Nunning, A. (Eds.) (2012). Travelling concepts for the study of culture. Berlim: Walter de Gruyter.

Nikolov, N. (1998). Interpretación social - psicológica de la obra de Diego Velazquez Las Meninas. Anuario de la Universidad de Sofía "San Clemente de Ojrida", 91, 3-26.

Nordmann, C. (2006). Bourdieu / Rancière. La politique entre philosophie et sociologie. Paris: Éditions Amsterdam.

Oddey, A. \& White, C. (Eds.) (2009). Modes of spectating. Bristol: Intellect.

Orellana, R. C. (2014). As palavras e as imagens: uma arqueologia da pintura em Foucault. Princípios. Revista de Filosofia, 21(35), 5-35. 
Passeron, J.-C. (1991/2006). L'usage faible des images. Enquêtes sur la réception de la peinture. In Le raisonnement sociologique. L'espace non-poppérien du raisonnement naturel (pp. 399- 442). Paris: Albin Michel.

Pecqueux, A. (2003). Indifférence, attention, latéralité. Ethnographie d'un concert de rap. In C. Barril, M. Carrel, J.-C. Guerrero \& A. Marquez (Eds.), Le Public en action. Usages et limites de la notion d' espace public en sciences sociales (pp. 319-337). Paris: L'Harmattan.

Portus, J. (2013). Diego Velázquez' Las Meninas. In Velázquez y la familia de Felipe IV, [1650-1680] (pp.126-129). Madrid: Museo Nacional del Prado.

Piette, A. (2009). Une action dans le mode mineur: une compétence impensée. In M. Beglivieri, M., Lafaye, C. \& Trom, D. (Eds.), Compétences critiques et sens de la justice (pp. 251-260). Paris: Economica.

Public, non-public: questions de méthodologie (2017). Interrogations. Revue Pluridisciplinaire de Sciences Humaines et Sociales, 24. Retirado de https://www.revue-interrogations. org/-No24-Public-non-public-questions.

Queiroz, J. P. (Ed.) (2017). Educação artística, desafios locais e globais. Proceedings from the VI Congresso Matéria-Prima. Lisboa: Faculty of Fine Arts, University of Lisbon (FBAUL).

Ramón-Laca, L. (2017). Modos de representación del espacio en Las Meninas. Locvs Amœnvs, 15, 91-103.

Rancière, J. (2008). Le spectateur émancipé. Paris: Ed. La Fabrique.

Raux, S. \& Dubuisson, D. (Eds.) (2015). Les nouveaux paradigmes du visuel. Dijon: Les Presses du Réel.

Ringmar, E. (2013a). Liberal barbarism: The European destruction of the palace of the emperor of China. Basingstoke: Palgrave Macmillan.

Ringmar, E. (2013b). Imperial vertigo and the themed experience: Yuanmingyuan and Disneyland compared. Human Geographies - Journal of Studies and Research in Human Geography, 7(1), 5-19.

Roueff, O. (2011). Les échelles de l'expérience. Temporalités, 14. Retirado de https://doi.org/10.4000/ temporalites. 1767

Salazar, N. B. \& Jayaram, K. (Eds.) (2016). Keywords of mobility. Critical engagements. Oxford: Berghahn.

San Sebastián convive con las esculturas de Manolo Valdés (2009, 08 de setembro). El Mundo. Retirado de https://www.elmundo.es/elmundo/2009/09/08/cultura/1252417171.html

Saurier, D. (2008). Savoirs et compétences des visiteurs: la réception de l'oeuvre de Rubens. Lien Social et Politiques, 60, 119-130.

Schnetz, S. \& Weiwei, A. (Eds.) (2013). Ai Weiwei: fairytale: a reader. Zurique: Jrp Ringier.

Schmickl, S. (2005). Les museum photographs de Thomas Struth. Une mise en abyme. Paris: Éditions de la Maison des Sciences de l'Homme.

Sequeira, Á. D. (2008). Públicos de arte pública. Estudo da recepção de arte pública no concelho de Almada. Tese de Mestrado, ISCTE-IUL Instituto Universitário de Lisboa, Lisboa, Portugal.

Siu, V. (1988). Castiglione and the Yuanrning Yuan collections. Orientations, 19(11), 72-79.

Sorace, C. (2014). China's last communist: Ai Weiwei. Critical Inquiry, 40(2), 396-419. 
Stratton-Pruitt, S. L. (Ed.) (2002). Velazquez's Las Meninas. Cambridge/Nova Iorque: Cambridge University Press.

Stratton-Pruitt, S. L. (Ed.) (2004). The Cambridge companion to Velázquez. Cambridge/Nova lorque: Cambridge University Press.

Sturken, M. \& Cartwright, L. (2001/2003). Practices of looking. An introduction to visual culture. Oxford e Nova Iorque: Oxford University Press.

Struth, T. \& Belting, H. (1993/2005). Museum photographs. Munique: Schirmer/Mosel.

Struth, T. \& Diego, E. de (2007). Making time. Nashville: Turner.

Struth, T. \& Benedictus, L. (2008, 18 de setembro). Thomas Struth's best shot: “I spent a week at the Prado trying to get this, doing eight hours a day". The Guardian. Retirado de https://www.theguardian.com/ culture/2008/sep/18/thomas.struth

Struth, T., Bezzola, T., Lingwood, J. \& Kruszynski, A. (2010). Photographs 1978-2010. Nova lorque: The Monacelli Press.

Thomas, G. M. (2008). The looting of Yuanming and the translation of Chinese art in Europe. NineteenthCentury Art Worldwide, 7(2), 1-40.

Thomas, N. (2016). The return of curiosity. What museums are good for in the twenty-first century. Londres: Reaktion Books / Chicago: University of Chicago Press.

Torres, M. V. (2009, 19 de dezembro). Galería fotográfica - Madrid IV (España) [Post em blogue]. Retirado de http://miguelveny.blogspot.com/2009/12/galeria-fotografica-blogspot-madrid-iv.html

Weiwei, A. \& Holzwarth, H. W. (Ed.) (2016). Ai Weiwei. Colónia: Taschen.

Weiwei, A., Tancock, J. \& Tung, S. H. (2019). Ai Weiwei. Beijing photographs, 1993-2003. Cambridge, MA: The MIT Press.

Wicks, R. (2010). Using artistic masterpieces as philosophical examples: The case of Las Meninas. The Journal of Aesthetics and Art Criticism, 68(3), 259-272.

Wilder, K. (2014). Las Meninas, Alois Riegl, and the 'problem' of group portraiture. In F. Dorsch \& D.-E. Ratiu (Eds.), Proceedings of the European Society for Aesthetic (pp. 402-421). Fribourg: European Society for Aesthetics (ESA).

Widmer, R. \& Kleesattel, I. (Eds.) (2018). Scripted culture. Digitalization and the cultural public sphere. Zurique: Diaphanes.

Villegas, R. (2010). Tres meninas en el laberinto de Foucault. Letras Históricas, 2, 11-36.

Véron, E. (1981). A produção de sentido. S. Paulo: Cultrix.

Veyne, P. (1988). Conduites sans croyance et oeuvres d'art sans spectateurs. Diogène, 143, 3-22.

Viollet, M. (2011). Les Comportements du spectateur comme enjeux de l'art contemporain. Tese de doutoramento, École Doctorale: Arts, Lettres, Langues, Philosophie, Communication, Unité de Recherche LLA-CREATIS, Université Toulouse 2 Le Mirail, França.

Vossilla, F. (2016). The Jesuit painter and his Emperor: some comments regarding Giuseppe Castiglione and the Qianlong Emperor. National Palace Museum Bulletin, 49, 69-87. 


\section{NOTA BIOGRÁFICA}

Idalina Conde é doutorada em Sociologia com especialização sobre arte e cultura. Trabalha igualmente sobre abordagens biográficas, mnemónicas e iconográficas paralelamente a uma linha sobre Europa e cultura contemporânea. Professora no Instituto Universitário de Lisboa. Investigadora no Centro de Investigação e Estudos de Sociologia (CIES - IUL).

ORCID: https://orcid.org/oooo-0o03-1577-9929

Email: idconde@gmail.com; Idalina.Conde@iscte-iul.pt

Morada: Avenida das Forças Armadas, 1649-026 Lisboa, Portugal

Submetido: 10/09/2019

Aceite: $31 / 11 / 2019$ 